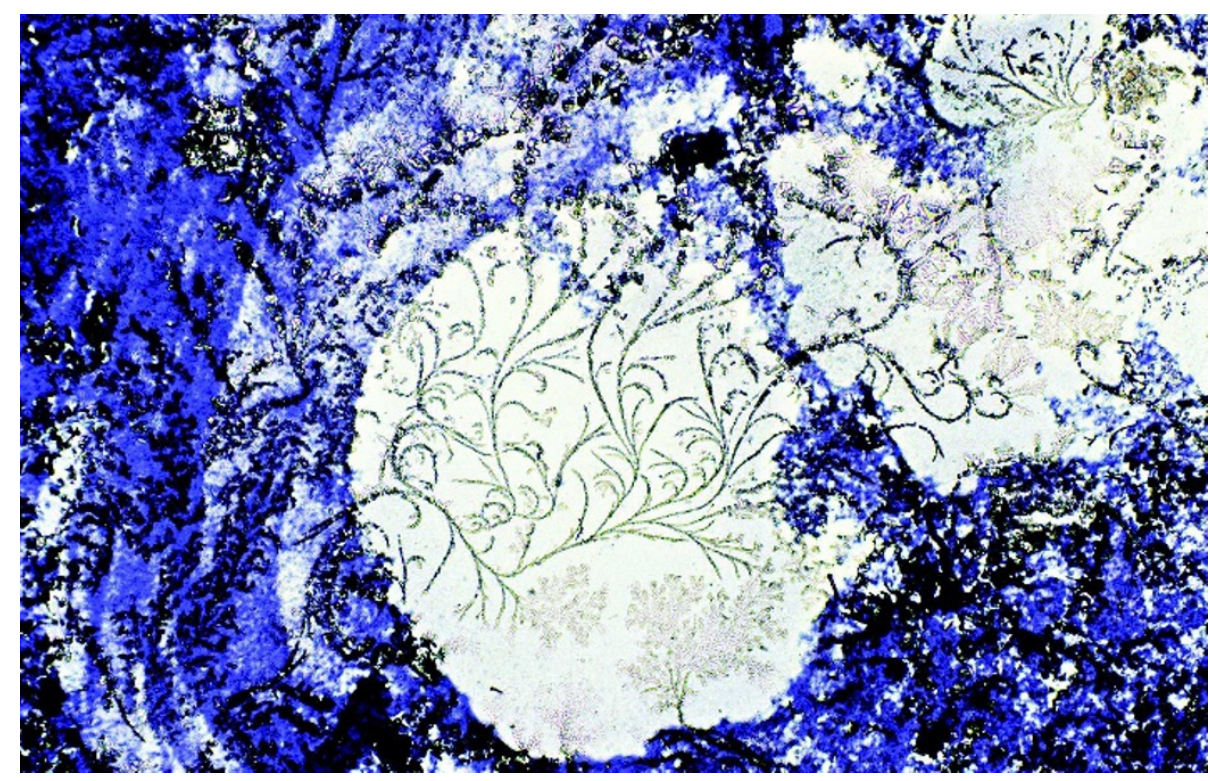

Oechsli's Untested Beliefs highlights the magnified fern-like branching of atropine, a muscle relaxant.

honed her techniques, Oechsli is drawn to the kaleidoscopic images for their own sake. An art lover, her most powerful photographs evoke familiar styles from famous abstract painters. "It pops to my mind that this style or this composition or this colour looks like [Robert] Motherwell or [Joan] Miró", she says. Some resemble still-life pictures - in Dance Double, magnified L-isoleucine morphs into ballet slippers dangling from their laces. Others are purely aesthetic. The technicolour leopard-skin knives of L-glutamic acid pierce into black voids in a dramatic work she calls Easter Island Fugue.

Oechsli considers herself an artist, but embraces the parallels between her two worlds. "Science is art and art is science," she says. "In both areas you have to be very disciplined. And both of those disciplines have no finish line."

Brendan Maher is Features and Commentary editor for Nature.

\title{
Bioethics laid bare
}

\author{
Future Bioethics: Overcoming Taboos, \\ Myths, and Dogmas \\ by Ronald A. Lindsay \\ Prometheus Books: 2008. 291 pp \\ $\$ 28.95 / £ 19.50$
}

Bioethical debate has seldom been more vibrant, or more important. Although some people dispute whether it is even a discipline, bioethics claims the high ground by tackling some of the most complex and sensitive issues confronting modern society. From discussions about abortion to end of life, bioethicists are there. They carry the flag for informed and contentious argument, be it over assisted reproduction, cloning or stemcell research. Ronald Lindsay, a lawyer with a doctorate in bioethics, is particularly well placed to bring his voice to the arena in his new book, Future Bioethics.
Given the range of topics that bioethicists cover, it is not surprising that emotions in the field run high. Discussions often begin from controversial positions that are entrenched in dogma. As the book's subtitle suggests, Lindsay's mission is to expose and debunk these myths. He does so in a book that is readable rather than obscure, and accessible to the interested lay person as well as to scholars in the field. Reckoning that progress is unlikely unless we can identify some common moral ground, he postulates that argument based on agreed norms can break the deadlock created by over-hyped language and untested dogma. What is needed, he argues, is "a wellreasoned, pragmatic approach to controversies in bioethics that avoids reliance on taboos, myths and dogma, whether these result from religious or ideological beliefs". These are fighting words, and Lindsay throws a number of powerful punches.
He starts by introducing the reader to his theoretical approach, which hinges on finding common ground and then applying 'common-sense reasoning' to it. Lindsay considers the main schools of moral reasoning and their inherent problems, and goes on to consider the relationship between morals and the law. He concludes that we must take account of moral norms, but shows that we also need to consider whether these are or can be incorporated into law, and if so, how.

After noting that bioethics embraces a wide range of topics, Lindsay selects five areas for consideration. For a European reader, the selection is somewhat unusual, but nonetheless fascinating. The least surprising inclusion is assisted dying. Given Lindsay's concern with debunking myths, it is an obvious starting point because debate in this area is often bound by entrenched ideological positions. Lindsay provides a thorough and entertaining account of the arguments that are dusted off by opponents whenever someone builds a case for allowing assisted dying. When legalization is opposed using the argument for the sanctity of life, he asks whether adherence to that principle serves its intended goal in all cases. For example, whereas we all agree that taking a life is wrong on the face of it, we may adopt this view because we assume the life is wanted by the person living it. He suggests that by pronouncing it is always wrong to take a life, even when that life may no longer be desired, is to misunderstand the obligations derived from the principle of respecting, protecting and furthering the interests of others. Thus, in exceptional cases where great suffering is involved and death is inevitable, he concludes that "death is not necessarily prejudicial to that person's interests".

It is with the 'slippery slope' argument against legislation that Lindsay engages most convincingly. Challenging the argument's theoretical basis, he points to evidence showing that allowing assisted dying does not inevitably mean that 'vulnerable' groups, such as the elderly or people with disabilities, would find themselves driven to seek death

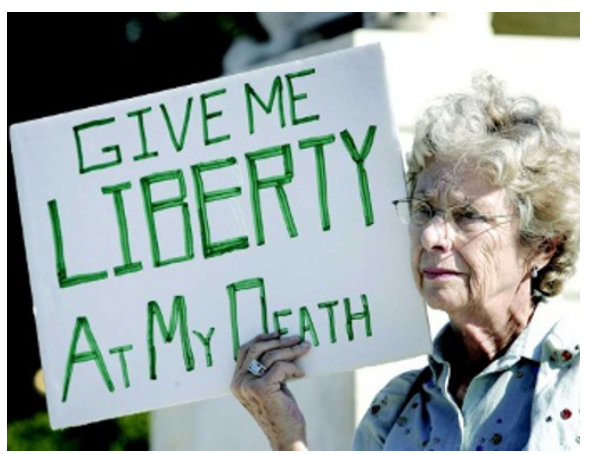


or that it would become commonplace. The US state of Oregon has legalized physicianassisted dying, the practice of which is meticulously monitored, and no evidence of any slippery slope has emerged. This is Lindsay's trump card - but it only argues for dying assisted by a physician, which is a problem if autonomy is the underpinning rationale for legalization.

Other topics covered include an interesting discussion of conscientious objectors in health care, the often thoroughly misinformed debate about genetically modified food, and discourses about genetic enhancement and stem-cell research. Each chapter is richly informed by factual and theoretical discussion and approached in the common-sense way that
Lindsay recommends. His use of practical examples to point out inconsistencies in arguments is vivid and gives the non-expert reader insight into these issues.

The book concludes by outlining a tentative theory of moral status. Perhaps the weakest part of the book, this reiterates how Lindsay thinks we should approach bioethical debate. We must, he argues, begin by identifying "the norms of the common morality", then "engage in a very rough weighing of the projected harms and benefits of following a proposed course of action". Then, we need to test the assumptions by examining their consequences, make them consistent and - of great importance - "understand the rationale for our norms". Lindsay does not pretend that this is easy, but he makes a good case that it is sensible and likely to be productive. Although I am less sure that such norms can be agreed, I endorse the need to think our positions through and to pay close attention to why we hold them, and the consequences of doing so. Overall, in his readable, reasoned and accessible book that challenges the taboos of bioethics, Lindsay achieves what he set out to do.

Sheila McLean is the International Bar Association Professor of Law and Ethics in Medicine at the School of Law, The University of Glasgow, Glasgow G12 8QQ, UK. She is author of Assisted Dying: Reflections on the Need for Law Reform.

e-mail: s.mclean@lbss.gla.ac.uk

\section{Q\&A: An insider's view of the body}

Radiologist Anders Persson of Linköping University Hospital, Sweden, reveals the body's hidden structures to clinicians by applying new techniques in magnetic resonance imaging and computed tomography to produce stunning computerenhanced three-dimensional images. The winner of the 2008 Lennart Nilsson Award for scientific photography, he tells Nature how visualization can revolutionize medicine.

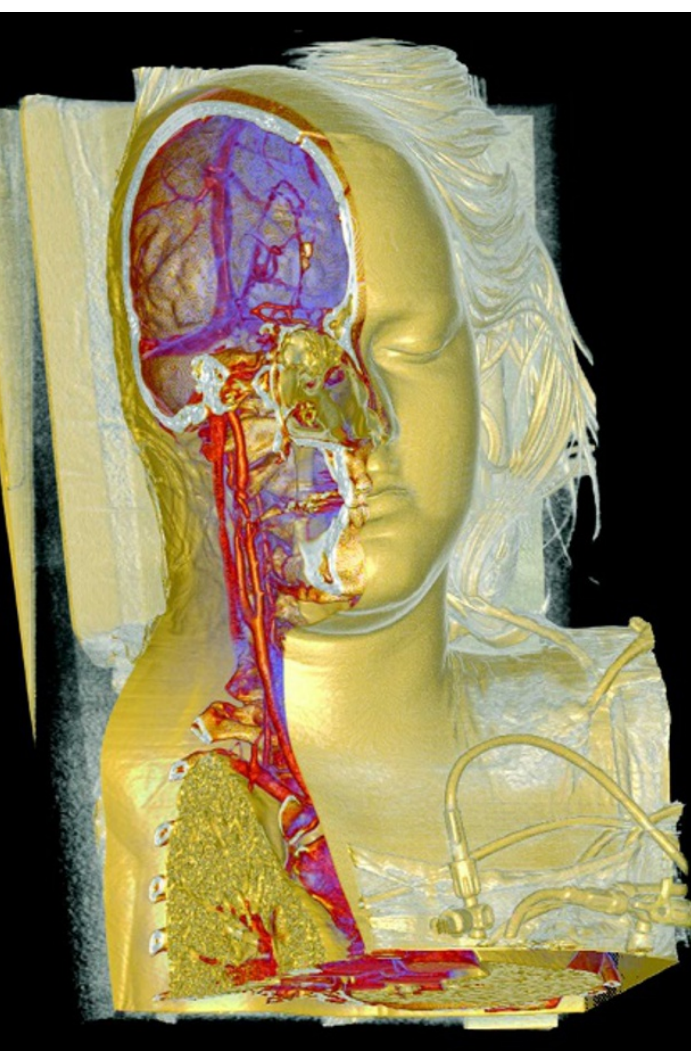

Anders Persson (right) has pioneered computerenhanced medical imaging to the benefit of patients and clinicians.

\section{What drives your work?}

Medical demand should lead technical research to the benefit of patients. I want to show the surgeon the real science, such as the true size, shape and colour of a vessel. Presenting precise and colourful details regarding the position, length and extent of aneurysms in arteries, for example, can save lives.

\section{Why are these techniques also useful for post-mortem imaging?}

Some forensic aspects, such as bone fractures, gas within wounds or metal under the skin are not visible in conventional autopsies. A virtual autopsy using threedimensional (3D) medical imaging thus provides invaluable information about the crime scene, helping to determine the cause of death and saving time.

\section{How did you become interested in medical photography?}

As a young radiologist, I realized that $3 \mathrm{D}$ and four-dimensional $\mathrm{X}$-ray visualization would rule the medical world in the future. Thirty years ago, I established a set of software functions for routine clinical use of $3 \mathrm{D}$ imaging, but it took many lectures to convince colleagues and vendors that we needed better visual tools.

\section{What are you working on today?}

I'm building a new tool called synthetic MRI, in which magnetic resonance images can be collected much more quickly for each patient. And they provide realistic values for tissue characteristics that will give a more quantitative picture of the development of pathology. I am also trying to sharpen techniques for visualizing the chemical constitution of the body, using multi-energy computed tomography.

\section{What inspires you?}

By providing beautiful images to benefit patients, I can give them vital information without scaring them. Also, the feedback I get from students stimulates me immensely to improve and explore new technical avenues.

Interview by Marta Paterlini, a writer based in Stockholm, Sweden.

e-mail: martapaterlini@nasw.org

See http://tinyurl.com/3zsclj for Anders Persson's 3D images. 